\title{
ACTITUDES Y COMPORTAMIENTOS DE LOS NATUSERS EN LOS CORREDORES VERDES URBANOS: RETOS Y OPORTUNIDADES. CASO DE ESTUDIO DEL PARC FLUVIAL DEL TÚRIA (ESPAÑA)
}

\author{
Mireia Alonso-Monasterio \\ Pau Alonso-Monasterio \\ María José Viñals \\ Departamento de Ingeniería Cartográfica, Geodesia y Fotogrametría. Universitat Politècnica de València. \\ mialfer@doctor.upv.es, paualfer@doctor.upv.es,mvinals@cgf.upv.es
}

\section{INTRODUCCIÓN}

A lo largo de su breve pero intensa historia, los cinturones y corredores verdes urbanos $1^{1}$ han estado relacionados con la mejora del entorno urbano y la renaturalización de las ciudades para dotarlas de mayor superficie de espacios verdes por habitante, mejorando así los índices de calidad de vida, y amortiguando la transición de la ciudad con su entorno rural o natural. De hecho, hoy en día en las ciudades, las zonas verdes cumplen funciones hedonistas, estéticas, urbanísticas, sociales, científicas y medioambientales. Más allá de satisfacer la necesidad demostrada que tenemos los seres humanos de estar en contacto con la naturaleza, es importante considerar que poner a disposición de las personas los corredores verdes urbanos, permite conservar mejor otros espacios naturales de mayor valor medioambiental.

En los últimos años, cada vez más ciudades están utilizando estos espacios no sólo para conectar diversas áreas urbanas entre sí o con zonas rurales y/o naturales próximas, sino también como cinturones verdes que ayudan a contener el crecimiento urbanístico desmesurado (Monclús, 2006). Además, con el incremento de la población en las zonas urbanas (tanto el actual como el que se prevé), los espacios verdes urbanos y suburbanos se están posicionando entre las áreas naturales más demandadas por los habitantes, ya que funcionan como zonas de recreo cercanas («Recreación de proximidad») donde practicar actividades al aire libre y disfrutar de la naturaleza, además de constituir vías de conexión alternativas y seguras para ciclistas, paseantes y otros usuarios.

1 En el presente artículo se habla de los corredores verdes urbanos como las zonas verdes que comunican aéreas naturales, lugares históricos o patrimoniales con zonas pobladas, normalmente a través de ríos que proporcionan zonas recreativas, así como los conocidos como cinturones verdes. 
Estos hechos conllevan la existencia de un gran número de usuarios ${ }^{2}$, incluso más elevado que algunas áreas protegidas (como Parques Naturales, Parques Nacionales o Reservas Naturales), que suelen estar alejadas de las ciudades. No obstante, y a pesar de acoger cada vez más usuarios, la mayoría de los corredores verdes urbanos no están considerados como áreas protegidas (se les suele concebir más como jardines o parques urbanos) y, por tanto, la mayoría no tienen desarrollado o redactado un Plan de Gestión, un Plan de Uso Público u otro tipo de documento que ayude a llevar a cabo una correcta gestión del público que utiliza el sitio. De hecho, la gestión de este tipo de áreas naturales no suele ir más allá de un mero mantenimiento y limpieza de instalaciones, retirada de basuras y trabajos de jardinería, sin tener en cuenta la conservación de los valores y funciones ecológicas de estos lugares, y tampoco la gestión del público.

\section{METODOLOGÍA}

Para conocer datos relativos a la gestión de los visitantes en los corredores verdes urbanos, se ha tomado como ejemplo el Parc Fluvial del Túria. Este corredor conecta la ciudad de Valencia (España) con los ocho municipios de los últimos $40 \mathrm{~km}$ que recorre el río antes de desembocar en el Mar Mediterráneo. En estos municipios se aglutina una población que asciende a más de 1 millón de habitantes. El corredor verde cuenta con diversas instalaciones: un sendero multi-usuario, señales direccionales e informativas y varias zonas de recreo con mesas de picnic, parques infantiles y equipamientos para hacer ejercicio. Este corredor está además integrado en un área protegida más grande, el Parc Natural del Túria, que cuenta con un Plan de Gestión de los Recursos Naturales; sin embargo, no cuenta con ningún documento en el que se aborde la gestión de las actividades recreativas o del uso público del sitio.

En este espacio se realizó una encuesta sobre una muestra de 1.950, en días laborables, fines de semana y festivos. El cuestionario se dividió en 3 partes: (1) información personal (género, edad, lugar de residencia, nivel de estudios y sector de trabajo), (2) actividades realizadas en el corredor verde normalmente y (3) opiniones y sentimientos en relación al Parc Fluvial del Túria. Los datos fueron analizados con el software SPSS.

\section{RESULTADOS: LOS NUEVOS NATUSERS O USUARIOS DE NATURALEZA}

Los resultados de la encuesta muestran que la mayoría de los visitantes del Parc Fluvial del Túria son vecinos de este corredor urbano, que acuden al sitio varias veces al mes (incluso a la semana), buscando principalmente un lugar donde desarrollar sus actividades favoritas y pasar su tiempo libre, solos o con la familia y/o amigos. Estos datos, junto con otros recopilados en la encuesta, indican que la principal motivación para visitar el sitio no sería aprender cosas sobre el lugar (ver y aprender sobre su fauna y flora, su biodiversidad, etc.) que es la propia de los visitantes de los espacios naturales protegidos), sino que es la de utilizar el sitio como escenario natural donde poder realizar diferentes actividades al aire

2 ES más real denominar «usuarios» que «visitantes» ya que el usuario hace un uso regular del espacio, no va de «visita». 
libre. En este sentido, el tipo de zona verde que constituye este corredor (cerca de núcleos urbanos muy poblados, con accesos sencillos y practicables) determina en gran medida que la mayoría de gente visite el sitio para utilizarlo como un lugar donde pasear, ir en bicicleta, correr, pasear a caballo o a las mascotas, etc. De hecho, todos los datos obtenidos en la encuesta refuerzan el concepto de usuarios habituales más que visitantes. Por ello, se puede afirmar que estamos ante una «nueva» categoría de visitantes, a los que se propone denominar natusers (usuarios de naturaleza): «personas que utilizan áreas naturales suburbanas como escenarios donde realizar actividades recreativas al aire libre fundamentalmente lúdicas o de entretenimiento y/o deportivas».

A pesar de que del concepto de natuser pueden desprenderse inicialmente connotaciones negativas en relación a sus implicaciones hacia la conservación de la naturaleza (puesto que su principal motivación no sería «conocer para conservar y proteger» el sitio, sino utilizarlo), esta categoría de usuarios podría suponer una oportunidad de conservación para el corredor verde. Así, considerando que la mayoría de usuarios procede de las poblaciones vecinas, el desarrollo de campañas de participación pública, involucrando asociaciones vecinales y organizaciones locales en la conservación y la gestión del corredor verde, tendrían una probabilidad de éxito mucho mayor. En este sentido, si los gestores del sitio consiguen que los vecinos del corredor verde lo consideren como algo propio, que les afecta directamente, si consiguen que les ataña, se conseguirá que éstos lo cuiden y se impliquen en su gestión, y exijan mejores niveles de conservación.

Otros resultados de la encuesta realizada tienen relación con la naturaleza multi-usuario de este corredor verde. En ellos, se constata que un considerable número de visitantes tuvo algún conflicto con otros usuarios en el corredor verde. Estos conflictos, que ya se habían detectado en otros sitios similares por autores como Church (2011), se debían mayoritariamente al hecho de ser un sendero para usuarios diversos con estilos de recreación diferentes en el que coinciden ciclistas, paseantes o corredores, jinetes a caballo y personas paseando al perro. Al no existir un plan de gestión que regule los usos recreativos, se detectan problemas que los códigos de conducta ética y los de etiqueta no alcanzan a resolver a base de actitudes y comportamientos voluntaristas.

El tercer bloque de resultados de la encuesta, muestra aspectos relacionados con el confort de los visitantes. Los datos indican la existencia de aspectos concretos de disconfort en la visita, como es la presencia de mosquitos y de basuras en distintos puntos del recorrido. Estos aspectos reafirman la necesidad de llevar a cabo una gestión del sitio coordinada que implique a las distintas instituciones y administraciones públicas que convergen en la zona. Normalmente, los corredores verdes atraviesan diversos términos municipales con sus distintas autoridades y administraciones, haciendo que la gestión sea especialmente compleja por la necesidad de coordinación y colaboración entre las instituciones implicadas.

\section{DISCUSIÓN Y CONCLUSIONES}

Existe abundante literatura en relación a la evidente necesidad de gestionar el uso público de las áreas naturales, pues muchas reciben miles de visitantes cada año. También está ampliamente documentada la existencia de herramientas que regulan el acceso y uso que 
se realiza de estos espacios para conseguir actitudes y comportamientos adecuados de los visitantes. Pues bien, todos estos conocimientos son perfectamente aplicables al caso de los corredores verdes y, en particular, al Parc Fluvial del Túria. Más allá de esta consideración general, se apunta a que, por el hecho de tratarse de usuarios que son, en su mayoría, vecinos de estos corredores verdes, se debe aspirar a que estas actitudes y comportamientos proactivos hacia la conservación y protección del sitio sean fruto del convencimiento derivado del sentido de pertenencia al lugar.

Entre los natusers, se han identificado básicamente dos grupos en función de sus motivaciones: los natusers hedonistas y los natusers deportivos. El grupo de natusers hedonistas incluye aquellos visitantes que acuden al sitio a andar, pasear al perro, ir en bicicleta, etc., buscando pasar un rato agradable al aire libre en contacto con la naturaleza. Las necesidades de naturaleza de este grupo se basan en motivaciones básicas, fáciles de alcanzar ya que no necesitan visitar lugares demasiado exclusivos para satisfacer sus expectativas. Son visitantes de un día (excursionistas), que no tienen pensado pernoctar cuando acuden al sitio. Este tipo de visitantes ama la naturaleza, no obstante sus actitudes y comportamientos podrían no ser siempre apropiados debido a la falta de conocimientos medioambientales pero presentan buena predisposición hacia actitudes y comportamientos proactivos de conservación y protección.

El grupo de natusers deportivos incluye aquellos usuarios que practican deportes en el corredor (runners, ciclistas de montaña o BTT, jinetes a caballo, etc.) y buscan mantenerse en forma y/o mejorar sus aptitudes y destrezas en el deporte (superación personal). Son visitantes regulares y frecuentes y su motivación está centrada en el propio ejercicio, mejorar su «marca personal» o estar en forma, lo que crea conflictos con otros visitantes que, en un momento dado, pueden interferir en el desarrollo de sus actividades.

Adicionalmente, hay que remarcar que los natusers prestan, en muchas ocasiones, mayor atención a los equipamientos necesarios para el desarrollo de la actividad (senderos, áreas de descanso, fuentes, etc.) que propiamente a los interpretativos (paneles, centros de visitantes, etc.). También se deduce de las encuestas su valoración positiva sobre la limpieza del lugar y el estado de conservación de los recursos.

Por otra parte, un fenómeno observado es la rapidez con la que se actualizan las informaciones relacionadas con este corredor verde gracias a las nuevas tecnologías y las redes sociales. De esta forma, los usuarios del Parc Fluvial del Túria crean numerosos contenidos sobre el sitio, proponiendo recorridos con coordenadas GPS en aplicaciones para smartphone gratuitas como Wikiloc o EveryTrail, compartiendo fotos de sus lugares preferidos o denunciando acumulación de basuras en algunos puntos, entre otros. Toda esta información actualmente se encuentra dispersa por la red, pero creando una plataforma que se coordinase desde la administración del Parque, podría contribuir positivamente a la conservación del sitio. Asimismo, la disponibilidad de este tipo de información también puede contribuir a la gestión de la capacidad de carga y de puntos de congestión del corredor, proponiendo rutas y lugares alternativos. También puede proporcionar información del tiempo, ofrecer datos curiosos, imágenes y fotos de usuarios, opiniones, etc. El objetivo sería que los visitantes usaran la web oficial del sitio (o la $a p p$ ) antes de visitarlo y que actualizasen su contenido con comentarios e información durante su visita o al finalizarla. 
Respecto a las motivaciones, actitudes y comportamientos de los natusers del Parc Fluvial del Túria observados y analizados, los principales resultados así como los retos y oportunidades que se desprenden de esta nueva tipología son los siguientes:

\begin{tabular}{|l|l|l|}
\hline Descriptores & $\begin{array}{c}\text { Natusers del Parc Fluvial } \\
\text { del Túria }\end{array}$ & \multicolumn{1}{|c|}{ Retos y oportunidades } \\
\hline $\begin{array}{l}\text { Cómo visitan el } \\
\text { sitio }\end{array}$ & $\begin{array}{l}\text { Con amigos, familia o en } \\
\text { solitario }\end{array}$ & $\begin{array}{l}\text {-Visitas espontáneas, sin planificar } \\
\text {-Pueden provocar congestión en ciertos puntos } \\
\text { del sitio }\end{array}$ \\
\hline $\begin{array}{l}\text { Fidelidad/ } \\
\text { frecuencia de } \\
\text { visitas }\end{array}$ & $\begin{array}{l}\text { A diario, semanal o mensu- } \\
\text { almente }\end{array}$ & $\begin{array}{l}\text {-Falta de interés por la señalización tradicional } \\
\text {-Alto potencial en los procesos de participación } \\
\text { pública } \\
\text {-Feed-back entre usuarios y gestores }\end{array}$ \\
\hline $\begin{array}{l}\text { Actividades que } \\
\text { desarrollan en el } \\
\text { corredor verde }\end{array}$ & $\begin{array}{l}\text { Principalmente deportivas } \\
\text { y lúdicas (bicicleta, pasear, } \\
\text { pasear al perro) }\end{array}$ & $\begin{array}{l}\text {-Conflictos entre usuarios } \\
\text {-Atención enfocada sobre todo a la actividad } \\
\text { que están desarrollando }\end{array}$ \\
\hline $\begin{array}{l}\text { Accesos y proxi- } \\
\text { midad }\end{array}$ & $\begin{array}{l}\text {-A pie y en bicicleta } \\
\text {-De los pueblos cercanos }\end{array}$ & $\begin{array}{l}\text {-Dificultad para prever la afluencia de visitantes } \\
\text {-Éxito de participación en actividades progra- } \\
\text { madas y/o de voluntariado } \\
\text {-Actividades de educación ambiental en colegi- } \\
\text { os cercanos } \\
\text {-Facilidad para crear un sentimiento de perte- } \\
\text { nencia al sitio }\end{array}$ \\
\hline $\begin{array}{l}\text { Actitudes y com- } \\
\text { portamientos }\end{array}$ & $\begin{array}{l}\text { Respeto hacia los recursos y } \\
\text { buena predisposición hacia } \\
\text { actitudes proactivas de con- } \\
\text { servación }\end{array}$ & $\begin{array}{l}\text {-Conflictos entre usuarios } \\
\text {-Concepto de parque urbano más que de } \\
\text { espacio natural }\end{array}$ \\
\hline
\end{tabular}

Finalmente, remarcar que la existencia de corredores verdes periurbanos conlleva unas consideraciones de gestión sensiblemente distintas a las habituales en espacios naturales protegidos. En primer lugar, considerar el elevado número de visitantes frecuentes que los utilizan como escenario para desarrollar distintas actividades, conjugado con el reto que supone la gestión de la conservación de la biodiversidad en estas condiciones. Se abre, por tanto, un nuevo campo de investigación en el diseño e implementación de herramientas de conservación y de gestión del uso público que sean adecuadas y eficientes para estas situaciones. 
